\title{
Características Morfológicas do Paspalum atratum cv. Pojuca Submetido ao Pastejo Rotacionado. Dinâmica de Perfilhamento e Elongação de Folhas ${ }^{1}$
}

\author{
Marcello Augusto Dias da Cunha1, Gilberto Gonçalves Leite ${ }^{2}$, José Mauro da Silva Diogo ${ }^{3}$, \\ Lúcio J. Vivaldi ${ }^{2,} 4$
}

\begin{abstract}
RESUMO - Este trabalho foi conduzido no Colégio Agrícola de Brasília - Distrito Federal e buscou avaliar a dinâmica do aparecimento e morte de perfilhos e elongação de folhas em três localizações da touceira (central, intermediária e periferia), do Paspalum atratum cv. Pojuca submetido ao pastejo rotacionado, com ciclo de 10 dias de utilização e 30 dias de descanso. Foram aplicados $40 \mathrm{~kg} / \mathrm{ha}$ de $\mathrm{N}$, na forma de sulfato de amônia antes da entrada dos animais nos piquetes em cada pastejo. As análises estatísticas basearam-se na utilização de um modelo hierárquico completo. A área de 3,2 ha foi dividida em dois grupos de quatro piquetes de 0,4 ha cada e mais duas áreas de $6 \mathrm{~m}^{2}$, contíguas às anteriores, onde não houve pastejo, para que se pudesse comparar os efeitos deste. A contagem de perfilhos vivos e mortos foi realizada em 120 quadrados de $0,25 \mathrm{~m}^{2}$, distribuídos nos oito piquetes e mais oito quadrados nas áreas contíguas onde não houve pastejo. O maior perfilhamento ocorreu no ciclo 2 coincidindo com o período de maior precipitação, porém apresentou baixa mortalidade de perfilhos durante todo o período avaliado. O desfolhamento não reduziu o aparecimento de perfilhos no início da fase vegetativa da pastagem. A elongação de folhas alcançou valores maiores nos ciclos 1 e 2 de pastejo e os mais baixos, nos ciclos 3 e 4 . As maiores elongações ocorreram nas porções periférica e entremeio e a menor, na região central da touceira.
\end{abstract}

Palavras-chave: dinâmica de crescimento, perfilhos

\section{Morphological Characteristics of Paspalum atratum cv. Pojuca Submitted to Rotational Grazing. Tiller Dynamics and Leaf Elongation}

\begin{abstract}
This experiment was conducted at the Brasília Agricultural College - Federal District, and studied the dynamics of appearance and death of tillers as well as leaf elongation in three positions of the stump (central, intermediate and peripheral) of Paspalum atratum cv. Pojuca, submitted to four rotational grazing cycle of 10 days use and 30 days resting. A descriptive analysis was applied using a hierarchical model. Nitrogen was applied at a rate of $40 \mathrm{~kg} / \mathrm{ha}$, in the form of ammonium sulfate before each grazing cycle. The area was divided in two sets of four pickets of 0.4 ha each and two other areas of about $6 \mathrm{~m}^{2}$ used as a reference for the purpose of quantifying the effect of grazing. The tillers were counted in 120 squares with $0.25 \mathrm{~m}^{2}$ area distributed in the eight pickets and the other eight in the non grazed areas. The highest tillering occurred during cycle 2, coinciding with the highest precipitation. The species showed a low level of tiller death during the studied period. Grazing did not reduce the tillering during the vegetative growth phase. Leaf elongation had its highest values in cycles 1 and 2 and lowest in cycles 3 and 4 . The highest elongations occurred in the periferic and middle positions and the lowest in the central position of the stump.
\end{abstract}

Key Words: growth dynamics, tillers

\section{Introdução}

A região dos Cerrados, com aproximadamente $2.064 .676 \mathrm{~km}^{2}$, ocupa lugar de destaque na produção agropecuária do país. Nela estão cerca de $44 \%$ do rebanho bovino nacional especializado nas atividades de produção de carne e, em menor escala, de leite (PRIMAVESI, 1992).

O manejo inadequado e a conseqüente degradação das pastagens cultivadas ou nativas tem levado pesquisadores e pecuaristas a procurarem alternativas para otimizarem a produção vegetal, visando melhorar o desempenho animal por unidade de área (RODRIGUES e REIS, 1995).

A disponibilidade ou oferta de forragem irá condicionar os rendimentos animais durante as diferentes épocas do ano (NABINGER, 1997). O acúmulo de matéria seca em pastagens estabelecidas advém do aumento das áreas foliares que, conseqüentemente, incrementam a produção de assimilados, bem como de acréscimo do número de perfilhos e elevação dos entrenós (GOMIDE, 1997). O perfilhamento é geral-

\footnotetext{
${ }^{1}$ Professor do Departamento de Agronomia da UPIS, Brasília - DF. E.mail: mcunha@onix.com.br

2 Pesquisador da EMBRAPA/Centro de Pesquisas Agropecuárias do Cerrado. C. Postal 08223,73301-970,Planaltina-DF. E.mail:leite@cpac.embrapa.br

${ }^{3}$ Professor da Faculdade de Agronomia e Medicina Veterinária. Universidade de Brasília - Brasília - DF. E.mail: diogojm@unb.br

4 Professor do Departamento de Estatística da Universidade de Brasília - Brasília, DF.
} 
mente um indicador de vigor e persistência de plantas forrageiras ou como uma variável resposta a práticas de manejo, como, por exemplo, adubação nitrogenada (MATHEW et al., 1995).

Em geral, o perfilhamento é reduzido pelo estresse hídrico (TURNER e BEGG, 1978), temperaturas altas, redução da quantidade de luz ou desfolhação parcial, afetando a emissão de novas gemas. Aspectos nutricionais, bem como época do ano, podem influenciar o perfilhamento. CECATO (1993), em estudos com Panicum maximum, verificou esses aspectos. O pastejo, em função de sua severidade, influi nas taxas de aparecimento e morte de perfilhos (YOUNGNER, 1972).

De acordo com os trabalhos de HAY e WALKER (1989), a taxa de elongação de folhas é responsável por $80 \%$ do crescimento em comprimento, $95 \%$ do peso seco e $99 \%$ da área foliar em plantas forrageiras. Portanto, justifica-se um estudo sobre a taxa de elongação de folhas, visto que ela contribui para o acúmulo de biomassa na pastagem.

O capim Pojuca é perene, de crescimento ereto, atingindo altura superior a 1,5 metros. As folhas são tenras, com a metade superior dobrada para baixo. A reprodução é apomítica e, na região central do Brasil, o florescimento ocorre de meados de fevereiro a meados de março. Sua capacidade de produção de forragem, em alguns locais, atingiu 26 toneladas de matéria seca por hectare.

O objetivo deste trabalho foi estudar a dinâmica de perfilhamento e elongação de folhas do Paspalum atratum cv. Pojuca submetido ao pastejo rotacionado, como fatores determinantes do potencial da pastagem.

\section{Material e Métodos}

Este trabalho foi conduzido em área experimental do Colégio Agrícola de Brasília, Distrito Federal, no período de novembro de 1997 a maio de 1998. A precipitação pluviométrica do período foi de $700 \mathrm{~mm}$ (Figura 1). Os dados de precipitação foram coletados na Estação Principal da Embrapa Cerrados - Brasília/ DF. Foram aplicados $40 \mathrm{~kg} / \mathrm{ha}$ de $\mathrm{N}$, na forma de sulfato de amônia antes de cada pastejo.

A gramínea estudada foi o Paspalum atratum cv. Pojuca, submetido ao pastejo rotacionado com 10 dias de utilização e 30 dias de descanso.

Uma área de 3,2 ha, já estabelecida, foi dividida em dois conjuntos de quatro piquetes de 0,4 ha cada, onde não houve pastejo, e mais duas exclusões de cerca de seis metros quadrados cada, usadas como referência para que se pudesse avaliar o efeito do pastejo.

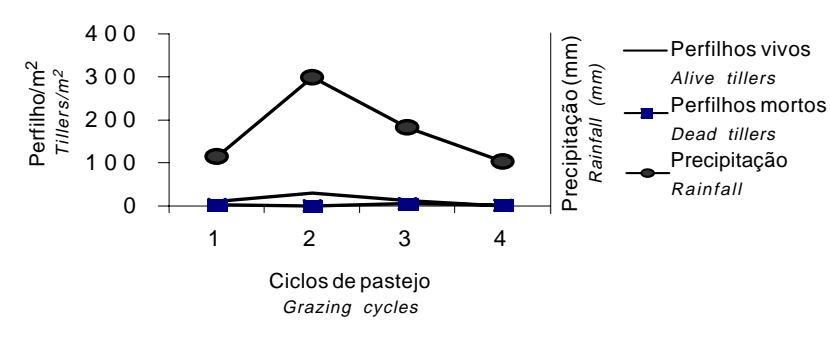

Figura 1 - Taxa de aparecimento e morte de perfilhos por metro quadrado durante o ciclo de pastejo em Paspalum atratum cv. Pojuca submetido ao pastejo rotacionado.

Figure 1 - Tillering and mortality rates $/ m^{2}$ occured during grazing cycles in Paspalum atratum cv. Pojuca submitted to a rotational grazing.

Foram demarcados aleatoriamente, em cada piquete, cinco linhas transectes. Em cada transecte, foram demarcados aleatoriamente três quadrados fixos de $0,25 \mathrm{~m}^{2}(0,50 \mathrm{~m} \times 0,50 \mathrm{~m})$. Em cada um destes, escolheu-se uma touceira e nelas foram selecionados três perfilhos individuais com características vegetativas semelhantes, localizados nas porções central, intermediária e periferia, respectivamente, identificados com fios de cores diferentes e monitorados durante todo o período avaliado, num total de 360 perfilhos tutorados. Foram feitas contagens de perfilhos vivos e mortos para a determinação da taxa de perfilhamento e mortalidade. Os resultados foram expressos em número de perfilhos por metro quadrado. As coletas foram executadas imediatamente antes e após a saída dos animais dos piquetes.

Marcou-se a folha mais jovem do perfilho e as demais, sucessivamente, na porção basal da lâmina e junção com a baínha, com tinta acrílica não lavável, para que se pudesse quantificar a elongação produzida no período. As medições foram feitas com régua graduada com precisão de $0,5 \mathrm{~cm}$.

Nas duas áreas de exclusão, foi demarcado aleatoriamente um transecte em cada. Em cada transecte, foram demarcados aleatoriamente quatro quadrados fixos de $0,25 \mathrm{~m}^{2}$. Para a avaliação desses parâmetros, foi usado o mesmo procedimento dos piquetes pastejados. Um total de 24 perfilhos foi monitorado nas exclusões. A pressão de pastejo utilizada variou entre 4 e $5 \%$ ( $4-5 \mathrm{~kg} \mathrm{MS} / 100 \mathrm{~kg} \mathrm{PV})$, tendo sido baseada na disponibilidade de matéria verde seca da forragem. O primeiro ciclo de pastejo ocorreu no 
Rev. bras. zootec.

período de 28/11/97 a 7/1/98, o segundo de 8/1/98 a $16 / 2 / 98$, o terceiro de $17 / 2 / 98$ a 28/3/98 e o quarto de $7 / 4 / 98$ a 17/5/98. Para a avaliação quantitativa das variáveis aparecimento e morte de perfilhos e elongação de folhas, utilizaram-se as fórmulas de BROWN (1983). Os resultados foram avaliados por meio de um modelo hierárquico completo. Utilizou-se análise de regressão e a PROC GLM do pacote estatístico SAS (contrastes) para avaliar a elongação de folhas nos perfilhos central, intermediário e periférico das touceiras.

\section{Resultados e Discussão}

Nos ciclos 1 e 2 de pastejo, a variável precipitação parece ter influenciado positivamente para que houvesse aumento no número de perfilhos emergidos e diminuição de perfilhos mortos da gramínea Paspalum atratum cv. Pojuca (Figura 1). MORALES et al. (1997), trabalhando com cornichão (Lotus corniculatus L.) cv. São Gabriel, verificaram que maiores disponibilidades hídricas podem contribuir positivamente para o acréscimo de biomassa por área da pastagem, com o aumento da densidade de perfilhos, proveniente de maior taxa de alongamento de folhas da haste principal. No ciclo 3, houve redução no aparecimento de perfilhos e no ciclo 4 seu valor foi nulo, provavelmente em decorrência da diminuição das chuvas na região.

A resposta quadrática para perfilhamento nas áreas sem pastejo $(\mathrm{P}>0,05)$ (Figura 2) mostra que a

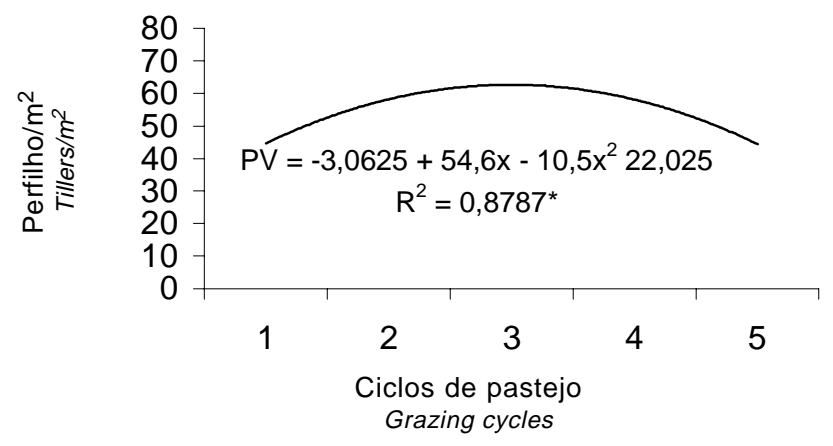

Figura 2 - Perfilhos vivos por metro quadrado em Paspalum atratum cv. Pojuca em ausência de pastejo.

Figure 2 - Live tillers per square meter in Paspalum atratum cv. Pojuca in non-pasture area. espécie apresenta produção crescente de perfilhos até a $13^{\mathrm{a}}$ semana de crescimento.

O perfilhamento mais elevado, nas áreas pastejadas $\left(29,2\right.$ perfilhos $\left./ \mathrm{m}^{2}\right)$, ocorreu no final do ciclo 2 e início do ciclo 3 , coincidindo com a $12^{\mathrm{a}}$ e $13^{\mathrm{a}}$ semanas de crescimento da forrageira. BARBOSA et al. (1996), trabalhando com Panicum maximum Jacq., observaram que cortes regulares promoviam acréscimo no número de perfilhos no dossel da pastagem. No presente estudo, a dinâmica de aparecimento e morte de perfilhos nas áreas com ou sem pastejo (Figuras 1 e 2) indicam que a gramínea se desenvolveu bem nos períodos de maiores precipitações.

Com a aproximação do final da estação chuvosa e, conseqüentemente, com a diminuição da precipitação, ciclo 3 , a partir da $17^{\mathrm{a}}$ semana, houve diminuição nas quantidades de perfilhos emergidos, sem que houvesse aumento no número de perfilhos mortos (Figuras 1 e 2). DIAS FILHO et al. (1989) verificaram que o efeito de estresse hídrico afetou o número de perfilhos por planta do capim colonião cv. Tobiatã, independentemente se foi imposto de forma crescente ou contínua. A baixa mortalidade de perfilhos (Figuras 1 e 3 ) apresentada pela forrageira é uma característica que deve ser melhor explorada no manejo da pastagem. NG et al. (1975) observou comportamento inverso, quando trabalharam com P. maximum var. Trichoglume, e, com o aumento do déficit hídrico, houve aumento na mortalidade de folhas e, conseqüentemente, no número de perfilhos mortos da pastagem.

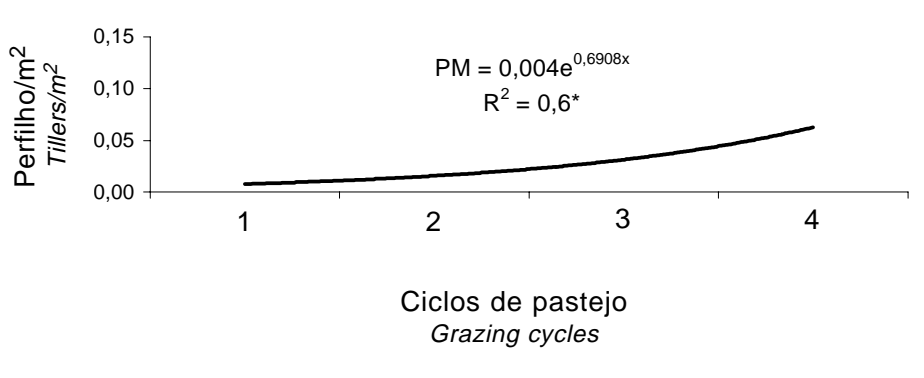

Figura 3 - Perfilhos mortos (PM) por metro quadrado em Paspalum atratum cv. Pojuca em ausência de pastejo.

Figure 3 - Tillers death per square meter in Paspalum atratum cv. Pojuca in non-pasture areas. 
A resposta exponencial $(\mathrm{P}>0,05)$ mostrou que a mortalidade de perfilhos para a pastagem não submetida a pastejo (Figura 3) foi sempre baixa, independentemente da época em que se efetuaram as observações. A baixa mortalidade de perfilhos tanto para as áreas pastejadas como para as sem pastejo demonstra boa longevidade da planta, garantindo produção de forragem nova até o período da estação seca seguinte. LEITE et al. (1997), em estudo com Echinocloa inflexa, gramínea nativa do Cerrado, também observaram haver baixa mortalidade de perfilhos durante a estação de crescimento da pastagem.

A diminuição no aparecimento de perfilhos vivos no ciclo 3 e ausência de perfilhos vivos no ciclo 4 pode estar relacionada com o equilíbrio entre as taxas de aparecimento e morte dos mesmos ao longo da estação de crescimento, bem como ao fim do ciclo da espécie, demonstrando que a pastagem provavelmente atingiu equilíbrio na produção e morte de tecidos. Isso foi observado por KORTE (1986), em trabalho com centeio perene submetido a duas frequências de pastejo.

A precipitação parece ter influenciado positivamente para que houvesse acréscimo na elongação de folhas de Paspalum atratum cv. Pojuca submetido ao pastejo (Figura 4). Não houve diferença $(\mathrm{P}>0,05)$ na elongação de folhas para os perfilhos localizados nas regiões do centro, intermediária e periferia da touceira.

As maiores elongações de folhas por perfilho nas

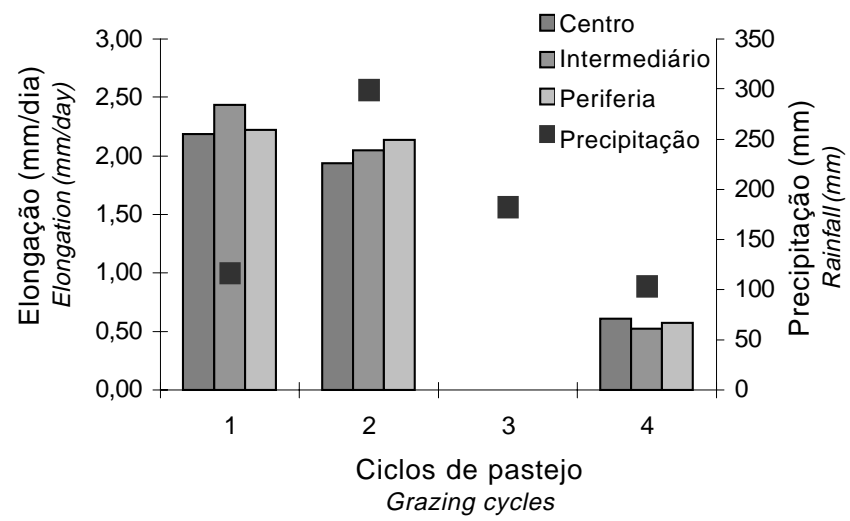

Figura 4 - Elongação de folhas $(\mathrm{mm})$ por dia, de acordo com a localização na touceira durante o ciclo de pastejo em pastagem de Paspalum atratum cv. Pojuca submetida ao pastejo rotacionado.

Figure 4 - Leaf elongation $(\mathrm{mm})$ per day in three positions of the stump of Paspalum atratum cv. Pojuca submitted to rotational grazing. áreas pastejadas ocorreram nos ciclos $1(2,19 ; 2,44$; e $2,22 \mathrm{~mm})$ e $2(1,94 ; 2,05$; e $2,13 \mathrm{~mm})$ e as menores, nos ciclos 3 (zero) e $4(0,61 ; 0,52$; e $0,58 \mathrm{~mm})$ nos perfilhos das regiões central, intermediária e periferia da touceira, respectivamente. Este fato provavelmente decorre em resposta aos altos índices pluviométricos ocorridos nos períodos iniciais, fluxo de tecidos promovido pelos animais em pastejo. PERES (1993) trabalhando com capim-Tangola (B. mutica $\times$ B. arrecta) observou que o déficit hídrico pode ocasionar uma redução na elongação de folhas. MURPHY e BRISKE (1992) relacionaram eliminação da dominância apical com possíveis aumentos do fluxo de tecidos, por meio do maior perfilhamento em decorrência do desenvolvimento de gemas axilares. No presente estudo, valores elevados para a elongação de folhas nos ciclos iniciais podem estar relacionados a este fator. Severidade, época da remoção, temperatura e genótipo da planta podem promover ou inibir esse fluxo de tecidos (FAVORETTO, 1993).

Nas áreas pastejadas, as mais baixas elongações de folhas ocorreram nos ciclos 3 e 4 e podem estar relacionadas ao hábito de pastejo dos animais que promoveram grande remoção de tecidos no período avaliado. Os animais pastejaram as mesmas áreas repetidamente. GRANT et al. (1989) observaram este aspecto de seletividade por parte dos animais em

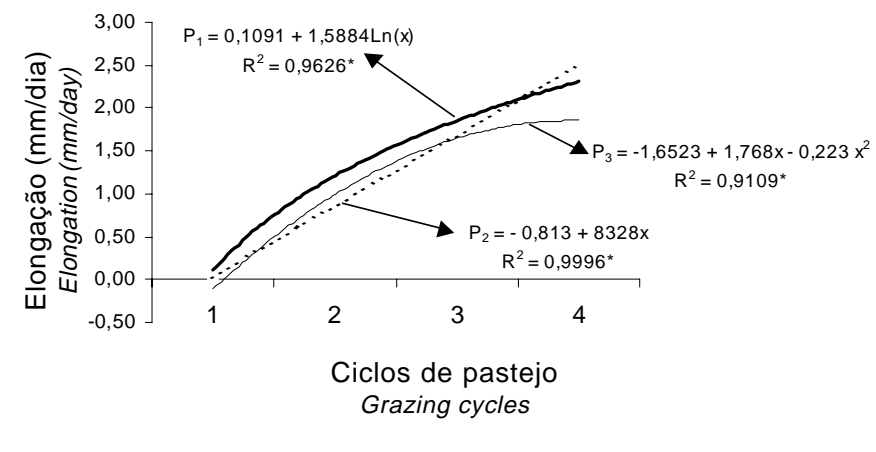

Figura 5 - Elongação de folhas ( $\mathrm{mm}$ ) por dia, nos perfilhos do centro (P1), intermediário (P2) e periferia (P3) da touceira em Paspalum atratum cv. Pojuca em ausência de pastejo.

Figura 5 - Leaf elongation $(\mathrm{mm})$ per day in three positions of the stump (central, intermediate and peripheral) of Paspalum atratum cv. Pojuca in non-pasture areas. 
Rev. bras. zootec.

pastejo. $\mathrm{O}$ inverso ocorreu nas áreas sem pastejo (Figura 5), em que as maiores elongações de folhas foram obtidas nos dois últimos ciclos, conforme as respostas logarítmicas, linear e quadráticas para os perfilhos localizados nas regiões central, intermediária e periferia da touceira, respectivamente.

Durante os ciclos 1 e 2, nas áreas pastejadas, verificou-se maior elongação numérica de folhas nas porções periférica e intermediária, ou seja, nas partes mais externas das touceiras (Figura 4). No mesmo período, a menor elongação de folhas ocorreu na região central da touceira. Os animais em pastejo, por meio da remoção de tecidos das partes das plantas, possibilitam a maior penetração de luz no dossel, podendo estimular a elongação nas partes mais externas da touceira. Segundo HUMPHREYS (1991), a remoção de excesso de folhagem, eliminando o sombreamento basal da touceira, pode interferir positivamente para que se obtenham acrécimos nos valores de matéria seca na pastagem, em virtude do aumento da atividade das gemas e capacidade fotossintética das folhas remanescentes.

Nas áreas sem pastejo (Figura 5), o perfilho central mostrou reposta logarítmica $(\mathrm{P}>0,05)$; o da intermediária, linear $(\mathrm{P}>0,05)$; e o da periferia, quadrática $(\mathrm{P}>0,05)$, com elongações máximas ocorridas no ciclo 4 , no final da estação chuvosa, diferindo dos resultados obtidos por LEITE et al. (1997), os quais verificaram que espécies nativas de cerrado submetidas à queima apresentaram maiores expansões de folhas no período de máxima precipitação. A partir do ciclo 4, os perfilhos localizados nas regiões do centro e periferia apresentaram numericamente as menores elongações diferindo do ciclo intermediário que manteve crescimento linear. A boa fertilidade do solo pode ter influenciado positivamente para que a elongação fosse alta durante todo o período de avaliação. Por outro lado, o sombreamento dos estratos basais da pastagem e a diminuição do regime hídrico, provavelmente, justificam a tendência de diminuição nas taxas de elongação de folhas nos perfilhos no ciclo 4 .

A elongação de folhas influenciou o processo de acúmulo de fitomassa e as características de rebrota da pastagem submetida ao pastejo, sendo alta no início da fase de crescimento. Observação visual permitiu constatar boa condição de cobertura do solo e controle de invasoras.

Segundo BIRCHAM e HODGSON (1983), este processo de acúmulo diário por perfilho, bem como a população de perfilhos, define os acréscimos de forragem em uma pastagem submetida a diferentes pressões de pastejo.

\section{Conclusões}

O Paspalum atratum cv. Pojuca tem potencial para ser utilizado em pastejo rotacionado, pois apresenta crescimento vigoroso no início da estação de crescimento e baixa mortalidade de perfilhos, sendo que o pastejo não interferiu no perfilhamento durante a fase vegetativa.

A elongação de folhas foi maior no primeiro ciclo, demonstrando que a forrageira apresenta crescimento vigoroso no início da estação de crescimento e início das chuvas, boa condição de cobertura e controle de invasoras, não obstante ter mostrado baixas quantidades de perfilhos vivos no mesmo período.

Sugere-se que sejam empregadas estratégias de manejo que aumentem o número de perfilhos e elongações de folhas em pastagens de Paspalum atratum cv. Pojuca submetido ao pastejo rotacionado.

\section{Referências Bibliográficas}

BARBOSA, M.A.A.F., DAMASCENO, J.C., CECATO, U. et al. Dinâmica do aparecimento, expansão e senescência de folhas em diferentes cultivares de Panicum maximum Jacq. In: REUNIÃO ANUAL DA SOCIEDADE BRASILEIRA DE ZOOTECNIA, 33, Fortaleza, 1996. Anais... Fortaleza: SBZ, 1996. p.101-103.

BIRCHAM, J.S., HODGSON, J. 1983. The influence of sward codition on rates of herbage growth and senescense in mixed swards under continuous stocking management. Grass and Forage Sci., 38(4):323-331.

BROWN, J.R. Leaf dynamics of little bluestem and brownseed paspalum in response to herbivory. Texas A \& M University, College Station, 1983. 104p. Thesis (Master) - Texas, USA, 1983.

CECATO, U. Influência da freqüência de corte, de níveis e formas de aplicação do nitrogênio sobre a produção, a composição bromatológica e algumas características da rebrota do capim-Aruana (Panicum maximum Jacq. cv. Aruana). Jaboticabal: FCAV, UNESP, 1993. 112p. Tese (Doutorado em Zootecnia) - Universidade Estadual Paulista, 1993.

DIAS FILHO, M.B., CORSI, M., CUSATO, S. 1989. Respostas morfológicas de Panicum maximum Jacq. cv. Tobiatã ao estresse hídrico. Pesq. Agropec. Bras., 24:893-898.

FAVORETTO, V. Adaptação de plantas forrageiras ao pastejo. In: SIMPÓSIO SOBRE ECOSSISTEMA DE PASTAGENS, 2, Jaboticabal, 1993. Anais... Jaboticabal: FUNEP, 1993. p.130-165.

GOMIDE, C.A., GOMIDE, J.A. Morfogênese e análise de crescimento de cultivares de Panicum maximum. In: REUNIÃO ANUAL DA SOCIEDADE BRASILEIRA DE ZOOTECNIA, 34, Juiz de Fora, 1997. Anais...Juiz de Fora: SBZ, 1997. v.2, p.403-405.

GRANT, S.A., ELSTON, D.A. BARTHRAM, G.T. 1989. Problems of estimating tissue turn over in grass swards in the presence of grazing animals. Grass and Forage Sci., 44:47-54.

HAY, R.K.M., WALKER, A.J. 1989. An introduction to the physiology of crop yield. New York: Longman Scientific e Technical. p.25-46. 
HUMPHREYS, L.R. 1991. Tropical pasture utilization. London: Cambridge University Press. p.46-65.

KORTE, C.J. 1986. Tillering in 'Grassland Nui’ perennial ryegrass swards. 2. Seasonal pattern of tillering and age of flowering tillers with two mowing frequencies. New Zealand J. Agric. Res., 29:629-638.

LEITE, G.G., TOMAZINI NETO, T, GOMES, A.C. et al. 1997. Dinâmica de perfilhos em gramíneas nativas dos cerrados do Distrito Federal submetidas à queima. R. Bras. Zootec., 26(4):691-696.

MATHEW, C., LEMAIRE, G., HAMILTON, N.R.S.et al. 1995. A modified self-thinning equation to describe size/ density relationship for defoliated swards. Annals of Botany, 76:579-587.

MORALES, A.S., NABINGER, C., MARASCHIN, G.E. et al. Efeito da disponibilidade hídrica sobre a morfogênese e a repartição de assimilados em $L$. corniculatus L. cv. São Gabriel. In: REUNIÃO ANUAL DA SOCIEDADE BRASILEIRA DE ZOOTECNIA, 34, Juiz de Fora, 1997. Anais...Juiz de Fora: SBZ, 1997. p.124-126.

MURPHY, J.S., BRISKE, D.D. 1992. Regulation of tillering by apical dominance: chronology, interpretative value, and current perspectives. J. Range Manag., 45:419-429.

NABINGER, C. Eficiência do uso de pastagens: disponibilidade e perdas de forragem. Fundamentos do pastejo rotacionado. In: SIMPÓSIO SOBRE MANEJO DA PASTAGEM, 14, 1997, Piracicaba. Anais... Piracicaba: FEALQ, 1997.p.213-252.

NG, T.T., WILSON, J.R., LUDLOW, M.M. 1975. Influence of water stress on water relations and growth of a tropical (C4) grass Panicum maximum var. trichoglume. Austr. J. Plant Physiol., 2:581-595.
PERES, J.R., BALSALOBRE, M.A., PAC-ELLO, P.R. 1993. Taxa de expansão e senescência de folhas de capim tangola (B. mutica $\times$ B. arrecta). Seminário apresentado na disciplina de Fisiologia de Plantas Forrageiras do curso de Pós-Graduação em Ciência Animal e Pastagem. Piracicaba: ESALQ/USP.

PRIMAVESI, A. 1992. Manejo ecológico de pastagens em regiões tropicais e subtropicais. 2.ed. São Paulo: Nobel. 184p.

RODRIGUES, L.R.A., REIS, R.A. Bases para o estabelecimento do manejo de capins do gênero Panicum. In: SIMPÓSIO SOBRE MANEJO DA PASTAGEM, 12, Piracicaba, 1995. Anais... Piracicaba: FEALQ, 1995. 345p.

TURNER, N.C., BEGG, J.E. 1978. Response of pasture plants to water deficits. In: WILSON, J.R. (Ed.) Plant relations in pastures. Melbourne, CSIRO. p.50-66.

YOUNGNER, V.B. 1972. Physiology of defoliation and regrowth. In: YOUNGNER, V.B., McKELL, C.M. (Eds.). The biology and utilization of grasses. New York: Academic Press Inc. p.293-303.

Recebido em: 21/03/00

Aceito em: 11/04/01 